\title{
Utilizando a Gamificação em uma intervenção pedagógica nas aulas de matemática do $7 .^{\circ}$ ano
}

\author{
Using Gamification in a pedagogical intervention in the 7th grade \\ mathematics classes
}

\author{
Amanda Martins (mandinhasbs@yahoo.com.br) \\ Professora da rede Estadual de Minas Gerais (SEE/MG) \\ Mayara Maia (mayara.maia89@gmail.com) \\ Professora da rede Estadual de Minas Gerais (SEE/MG) \\ Douglas da Silva Tinti (tinti@ufop.edu.br) \\ Programa de Pós-Graduação em Educação Matemática (PPGEDMAT) \\ Universidade Federal de Ouro Preto (UFOP)
}

\begin{abstract}
Resumo:
O presente relato de experiência apresenta uma intervenção pedagógica realizada em uma turma de $7 .^{\circ}$ ano de uma escola estadual de Minas Gerais, com o uso da Gamificação, para abordar os Números Inteiros e as quatro operações. Nesse sentido, objetiva-se apresentar uma possibilidade de utilização da Gamificação nas aulas de matemática. A proposta emergiu das discussões realizadas em uma disciplina de Metodologias Ativas de Ensino e Aprendizagem de um Mestrado Profissional em Educação Matemática. Apresenta-se a estratégia da Gamificação por meio de um jogo de cartas com códigos QR (quick response). Observou-se que a utilização de elementos dos games, em uma ação didática, pode motivar, de forma lúdica, os alunos para a ação e a compreensão do conteúdo. Desse modo, o relato sinaliza que a proposta da Gamificação pode ser enriquecedora no contexto escolar por incentivar os alunos a aprenderem de forma autônoma e participativa.
\end{abstract}

Palavras-chave: Metodologias Ativas; Gamificação; Educação Matemática.

\begin{abstract}
:
The present experience report presents a pedagogical intervention carried out in a seventh year class from a state school in Minas Gerais with the use of gamification in math classes. The proposal emerged fron the discussions reld in a dicipline of active teaching and learning methodologies for a professional master's degree in mathematical education. The gamification strategy is presented through a qr code card game (quick response). It was observed that the use of game elements in a didactic action, can motivate students to act and understand the content in a lucid way. Thus, the report
\end{abstract}


indicates that the proposal of gamification can be enriching in the school context by encouraging students to learn in na autonomous and participatory way.

Keywords: Active Methodologies, Gamification, Math Education.

\section{INTRODUÇÃO}

Este relato foi motivado pela proposta da disciplina de Metodologias Ativas na Formação e na Prática do Professor de Matemática, ministrada no primeiro semestre de 2019 do curso Mestrado Profissional em Educação Matemática da Universidade Federal de Ouro Preto, pelo terceiro autor.

A referida disciplina possui carga horária de 60 horas e tem por objetivo estudar metodologias de ensino que proporcionem ferramentas que possam auxiliar as práticas pedagógicas dos professores e, consequentemente, mobilizar aprendizagens nos estudantes da Educação Básica.

Além de discussões teóricas sobre as Metodologias Ativas, foi sugerida uma vivência de uma das metodologias no contexto escolar. Nesse sentido, a primeira e a segunda autora deste relato foram mobilizadas a elaborar e implementar uma proposta envolvendo a Gamificação.

A proposta foi desenvolvida como uma intervenção pedagógica, a partir dos resultados da avaliação diagnóstica realizada no início do ano de 2019 com uma turma do $7 .^{\circ}$ ano de uma escola pública da cidade Conselheiro Lafaiete com o intuito de: i) desenvolver habilidades matemáticas e raciocínio rápido; ii) organizar e registrar o pensamento matemático e a capacidade de compreender tabelas; iii) interpretar e solucionar problemas; iv) trabalhar o raciocínio lógico, a capacidade de sistematizar e interagir socialmente; v) resolver cálculos mentalmente; vi) desenvolver estratégias de jogo.

Assim sendo, o presente relato de experiência tem por objetivo apresentar uma possibilidade de utilização da Gamificação nas aulas de matemática. Para tanto, 
apresentaremos, a seguir, algumas reflexões teóricas que alicerçaram a prática e esta exposição.

\section{REFLEXÕES SOBRE GAMES E GAMIFICAÇÃO: FUNDAMENTOS E CONTEXTOS}

Na sequência, serão apresentadas algumas reflexões sobre games e Gamificação, com vistas a refletir sobre os elementos que compõem essa abordagem bem como sobre a importância do planejamento docente para o bom desenvolvimento da proposta pedagógica.

\section{$2.1 \quad G A M E S$}

Segundo Suits (1967) jogos, ou do inglês games, é uma atividade cuja natureza possui pontuação, vidas, níveis, recompensas e que tem como propósitos a diversão e o entretenimento. Essa atividade submete o jogador a suas regras e estabelece quem vence e quem perde. A finalidade de um jogo, podemos dizer, é ganhar o jogo.

Para esse autor, todo jogo possui três elementos: o primeiro é que todo jogo tem uma intenção pré-lusória, ou seja, antes de jogar, as pessoas já sabem o contento da diversão; o segundo é que todo jogo tem regras construtivas, e as pessoas as aceitam antes de ele iniciar; e, por fim, o objetivo do jogo é ganhar.

\subsection{GAMIFICAÇÃO}

Originário do termo inglês gamification, trata-se do uso de técnicas de jogos para propor mudanças de comportamento e engajamento. A Gamificação possui componentes importantes tais como o uso de elementos de jogos e as técnicas de designer de jogos em um contexto que não é de jogos. Independente do contexto de aplicação, a Gamificação pode ser entendida como um meio de cativar as pessoas a executarem uma atividade e progredirem nela. O desenvolvimento de habilidades e competências necessárias aos profissionais no mercado de trabalho, por exemplo, pode ser trabalhado com a Gamificação. Segundo Mattar (2010, p. 14): 
Saber aprender (e rapidamente), trabalhar em grupo, colaborar, compartilhar, ter iniciativa, inovação, criatividade, senso crítico, saber resolver problemas, tomar decisões (rápidas e baseadas em informações geralmente incompletas), lidar com a tecnologia, ser capaz de filtrar a informação etc. são habilidades que, em geral, não são ensinadas nas escolas. Pelo contrário: as escolas de hoje parecem planejadas para matar a criatividade.

O uso de Metodologias Ativas na educação, tais como a Gamificação, se justifica não apenas por serem estratégias de ensino que buscam a participação ativa do aluno na realização da atividade proposta, mas por proporem que ele conquiste a autonomia de construir conhecimento de maneira que esse tenha mais significado. O professor, então, passa a ter um papel secundário, ou seja, o de mediação. Conforme Araújo (2015, p. 6) pontua: "estabeleçamos então que a metodologia ativa está centrada no aluno, posto que sua aprendizagem torna-se protagonista, secundarizando-se o ensino, que fazia protagonizar o professor".

Corroborando essa ideia, Rech (2016, p. 41), destaca que:

[...] pode-se entender que as Metodologias Ativas baseiam-se em formas de desenvolver o processo de aprender, utilizando experiências reais ou simuladas, visando às condições de solucionar, com sucesso, desafios advindos das atividades essenciais da prática social, em diferentes contextos.

No âmbito educacional, a Gamificação vem ganhando espaço e tem como objetivo incentivar os alunos para que aprendam de forma autônoma e participativa. Kopfler, Osterweil e Salen (2008, p. 1) afirmam que:

Aqueles que acreditam no uso de games em educação, geralmente partem de algumas concepções gerais. Eles observam que os jogadores exibem, regularmente, elementos como persistência, assumem riscos, atenção a detalhes, assim como a habilidade de se resolver problemas. Elementos esses que se acredita serem ideais se demonstrados regularmente no ambiente escolar. Eles também entendem que ambientes de jogos eletrônicos permitem ao jogador a construção de entendimento ativo, no ritmo de cada um e que, jogos bem desenvolvidos, permitem ao aluno avançar por diferentes caminhos, de diferentes formas, em sintonia com os interesses de habilidades de cada jogador, enquanto fomentam a colaboração e aprendizagem em tempo real.

Essa proposta de ensino vem ao encontro das necessidades atuais dos alunos, uma vez que estamos em uma era em que a sociedade tem a tecnologia e a internet como pontos geradores de informação, comunicação, interatividade e, até mesmo, de aprendizagem. 
Segundo Gee (2009), as atividades interativas dos jogos são ferramentas que motivam e engajam seus usuários de modo que fiquem por horas em uma tarefa, com a finalidade de atingir um objetivo.

Portanto, os games incorporados pedagogicamente devem ser utilizados não por mera exigência tecnológica ou curricular, mas pelo caráter altamente educativo e saudável. Trataremos a seguir de algumas possibilidades apresentadas nos games que propiciam o processo de aprendizagem de forma contextualizada, engajando os jogadores a interagir com o meio, com a situação e com outros indivíduos.

\subsection{PRINCÍPIOS DE APRENDIZAGEM DOS JOGOS}

Segundo Gee (2004, p. 168), os jogos apresentam características que ajudam no desenvolvimento de habilidades dos jogadores "em um nível mais profundo, porém o desafio e a aprendizagem são em grande parte aquilo que torna os videogames motivadores e divertidos".

De acordo com este mesmo autor, os princípios podem ser descritos da seguinte forma:

a) Identidade - Aprender algo em qualquer campo requer que o indivíduo assuma uma identidade, um compromisso de ver e valorizar o trabalho de tal campo. Nesse contexto, "os jogadores se comprometem com o novo mundo virtual no qual vivem, aprendem e agem através de seu compromisso com sua nova identidade” (GEE, 2004, p. 170).

b) Interação - Nos jogos nada acontece sem que o jogador tome decisões e aja. E o jogo, conforme a atitude do jogador, oferece feedbacks e novos problemas. Em jogos online, os jogadores interagem entre si, planejando ações e estratégias, entre outras habilidades.

c) Produção - Nos jogos, os jogadores produzem ações e redesenham as histórias, individualmente ou em grupo.

d) Riscos - Os jogadores são encorajados a correr riscos, experimentar, explorar; se erram, podem voltar atrás e tentar novamente até acertarem. 
e) Problemas - Os jogadores estão sempre enfrentando novos problemas e precisam estar prontos para desenvolver soluções que os elevem de nível, nos jogos.

f) Desafio e consolidação - Os jogos estimulam o desafio por meio de problematizações que incitam o jogador a aplicar o conhecimento atingido anteriormente.

\subsection{PLANEJAMENTO DE UMA AULA GAMIFICADA}

Seguindo a perspectiva da Teoria da Diversão, do designer de games Ralph Koster, em que este faz a combinação de bom humor com uma pequena provocação para uma mudança de comportamento por meio da criatividade, construímos a atividade usando os elementos de Gamificação para promover uma mudança no comportamento dos alunos em relação à matemática.

Os Números Inteiros foram abordados por meio de atividades que envolviam representação geométrica, bem como as operações de adição, subtração, multiplicação e divisão.

Para desenvolver o planejamento de uma aula gamificada, usamos as ferramentas de um designer de jogos (game designer). Além disso, adotamos uma postura pedagógica em relação às possibilidades que os jogos proporcionam ao jogador. Busarello (2016) relaciona quatro elementos que norteiam a aplicação da metodologia de aprendizagem da Gamificação, a saber:

(I) Embasar a atividade em um ou mais jogos a fim de que o indivíduo queira gastar energia e tempo.

(II) Criar regras necessárias para o desenrolar da atividade e aliadas a objetivos e conquistas.

(III) Propor uma estética atrativa sobre a experiência.

(IV) Pensar que é um jogo, de forma que uma tarefa entediante e monótona se torne motivacional e contagiante através da apropriação de elementos de cooperação, de uma narrativa ou pano de fundo envolvente e, em alguns momentos, da articulação de competições. 
Considerando o exposto, detalharemos a seguir a proposta de Gamificação por nós elaborada e desenvolvida em sala de aula.

\section{DETALHAMENTO DA PROPOSTA}

\subsection{PLANEJAMENTO DA ATIVIDADE PELO PROFESSOR}

Para construir os códigos QR, acessamos o site ${ }^{1}$ gerador de QR Code, de aceso gratuito com número ilimitado de criações. Nele é possível criar códigos que contenham imagens ou texto. Além disso, é possível escolher a cor que o código gerado ficará.

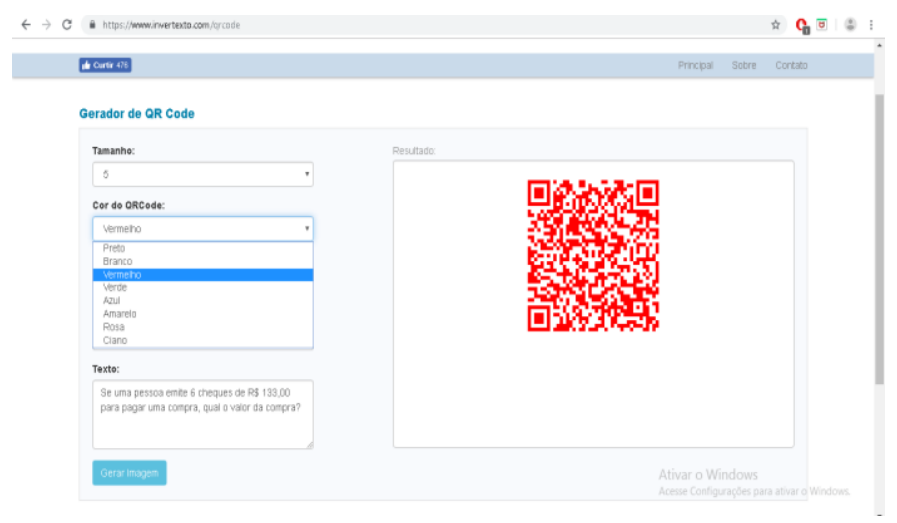

Figura 2 - Gerador de código QR

Para confeccionar as cartas, cortamos retângulos de $10 \mathrm{~cm}$ x $15 \mathrm{~cm}$ e colamos em uma parte o código e, no verso, a imagem relacionada à questão proposta.
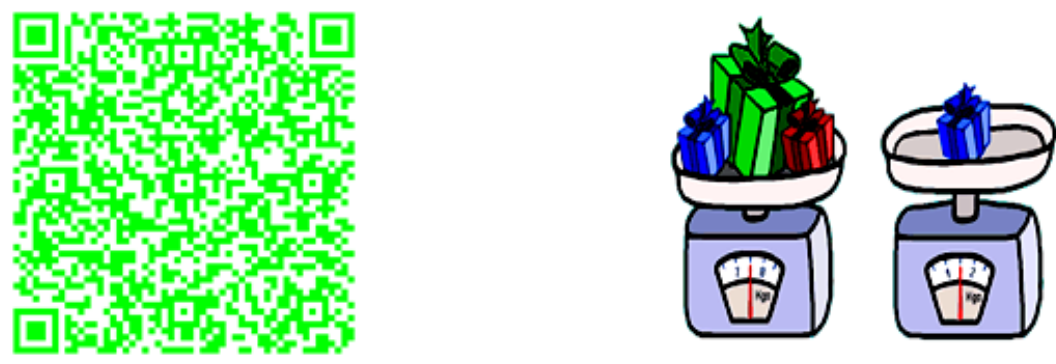

${ }^{1}$ Disponível em: http//www.invertexto.com/qrcode. Acesso em: 01 jul.2019. 


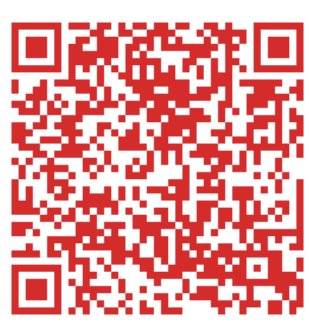

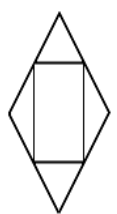
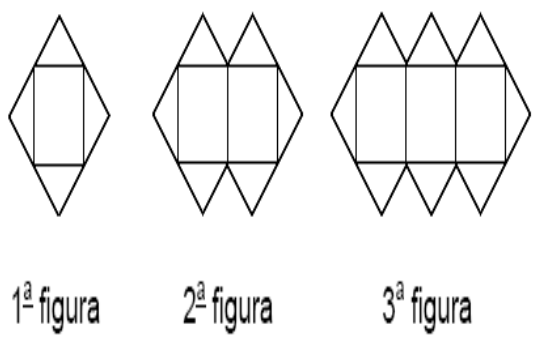

\section{2 ? figura}

\section{$3^{\text {a figura }}$}

Figura 3 - Modelo para impressão dos cartões

Construímos nossa moeda, o Matematicon M\$, com imagens encontradas no Google, utilizamos a moeda de $1 \mathrm{M} \$$, a nota de $5 \mathrm{M} \$$ e a de $10 \mathrm{M} \$$. Cada equipe recebeu, inicialmente, M\$20 em notas e moedas e, ao evoluir no jogo, poderia trocar as moedas por notas para facilitar as operações.

Para montar o jogo, as cartas foram divididas em quatro níveis, a saber:

- Fase 1 - Código QR Preto - M\$1 por acerto.

- Fase 2 - Código QR Vermelho - M\$2 por acerto.

- Fase 3 - Código QR Verde - M\$3 por acerto.

- Fase 4 - Código QR Azul - M\$5 por acerto.

Para mudar de fase, a equipe deveria acertar uma charada matemática que seria sorteada por um membro da equipe. Além disso, o time deveria ter: Fase 2 - M\$23, Fase $3-\mathrm{M} \$ 29$ e na Fase $4-\mathrm{M} \$ 35$.

A equipe que chegasse em 45 moedas primeiro e acertasse a charada da vitória seria a vencedora do game.

Em seguida algumas perguntas contidas nas cartas e as charadas utilizadas nas fases:

- Fase 1 - Um aluno reparou que em sua régua de $30 \mathrm{~cm}$ de comprimento havia uma formiga, que se encontrava na marca de $5 \mathrm{~cm}$. A formiga andou $17 \mathrm{~cm}$ para frente e, em seguida, voltou $3 \mathrm{~cm}$ e parou. A que distância ela se encontrava do ponto $0 \mathrm{~cm}$ quando parou? 
- Fase 2 - O cão da Flora subiu uma escada e sentou-se no $10 .^{\circ}$ degrau. O gato do Tomás sentou-se 3 degraus abaixo do cão. O gato ficou sentado no degrau do meio da escada. Quantos degraus tem a escada?

- Fase 3 - Em um bairro vivem exatamente 80 famílias. Em 40 destas famílias há uma criança. Metade das famílias restantes tem duas crianças. Os outros casais não têm filhos. Quantas crianças têm no bairro?

- Fase 4 - Quantas dúzias de ovos equivalem a 156 ovos?

- Charada - Se 3 gatos matam 3 ratos em 3 minutos, quanto tempo levarão 100 gatos para matar 100 ratos?

\subsection{ETAPAS DO DESENVOLVIMENTO DA PROPOSTA}

Para iniciar a atividade, os alunos foram divididos em grupos de até cinco pessoas, e cada grupo teve acesso a, pelo menos, um celular com o aplicativo de leitura do código QR.

Era indispensável que cada membro do grupo tivesse uma função, por exemplo:

a) fiscal das moedas que os outros grupos receberam do banco;

b) responsável pela leitura do código;

c) responsável pelo dinheiro do grupo;

d) responsável por orientar quem iria buscar a carta do nível;

e) responsável, com o auxílio dos demais membros do grupo, por resolver a atividade.

Inicialmente foi entregue uma cartolina e proposto que cada equipe criasse seu Avatar e desse um nome para o grupo. O desenho foi fixado no quadro para que todos os participantes vissem.

As cartas contendo os códigos foram dispostas em cima de uma mesa central de acordo com o nível em que estivessem os grupos. Todos os grupos começaram com 
M\$20. Para iniciar, cada grupo teve que jogar um dado. Quem tirou o maior número foi o primeiro a pegar uma carta. Caso houvesse empate, os grupos em questão deveriam lançar o dado novamente até desempatarem.

Ficou decidido que um aluno da primeira equipe deveria escolher uma carta e ativar o leitor de QR no celular. Cada carta possuía um desafio. Após ser feita a leitura do desafio, o aluno, juntamente com seu grupo, teve até três minutos para solucionar o desafio que estava na carta escolhida.

\section{APRESENTAÇÃO DA PRÁTICA}

A atividade de intervenção pedagógica foi desenvolvida em uma escola estadual da cidade de Conselheiro Lafaiete, interior de Minas Gerais, em uma turma de $7 .^{\circ}$ ano com 20 alunos, sendo que 5 faltaram no dia. Dessa forma, estiveram presentes 15 participantes.

A primeira autora desse relato atua como docente da turma. A atividade aconteceu em dois horários de aula seguidos (100 minutos), espaçados somente pelo horário do intervalo para o recreio (20 minutos).

Iniciou-se a apresentação da proposta de atividade, dividindo os alunos em grupos de cinco componentes cada. Cada grupo recebeu uma folha com as regras da atividade que foram lidas com os alunos pelas professoras mediadoras.

O primeiro passo foi a elaboração do Avatar e a criação do nome das equipes. Para isso foram disponibilizados dez minutos. Um membro de cada grupo, ao final desse tempo, foi à frente da turma e apresentou o nome de sua equipe e seu Avatar, colando-o no quadro.

Feitas as apresentações, os fiscais de cada equipe acompanharam a entrega e receberam as 20 moedas. Para iniciar a atividade, cada equipe jogou o dado para definir qual começaria. A equipe que ganhou no jogo de dados elegeu um membro dela que foi até a mesa central para pegar a primeira carta. Outro componente do grupo já estava com o aplicativo de leitura de código QR aberto para fazer a leitura. O tempo para desenvolver e responder a questão era de três minutos. Assim foi acontecendo com as 
outras equipes, uma por vez. Se a equipe acertava, ganhava as moedas; se não sabia responder, passava a vez para a próxima equipe.

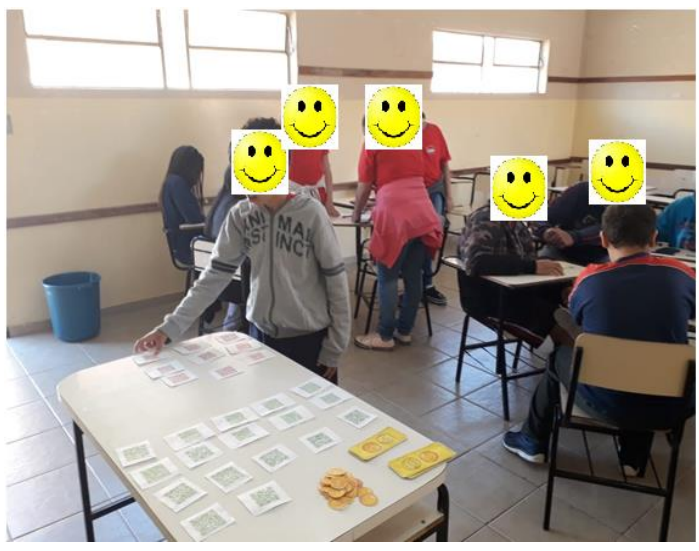

Figura 4 - Aluno escolhendo a carta para sua equipe

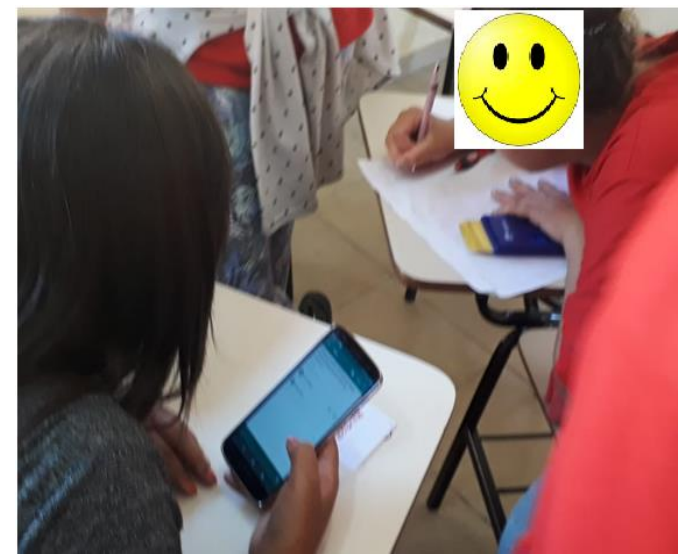

Figura 5 - Aluno escolhendo a carta para sua equipe

Após esta etapa, foi realizada a de premiação. Cada membro da equipe vencedora recebeu uma caixa de bombom e guloseimas, e os membros das outras duas equipes ganharam um pacote com guloseimas.

Ao final, foi proposta uma roda de conversa com os alunos. Com essa ação foi possível verificar, por meio das falas, que os estudantes sinalizaram ter tido grande interesse em realizar atividade no formato proposto, superando o tradicional modelo de aula pautado em definição, exemplos e exercícios. Além disso, os alunos relataram que essa proposta de aula havia sido muito divertida e envolvente, possibilitando a interação com os demais colegas.

\section{CONSIDERAÇÕES FINAIS}

A proposta da Gamificação foi enriquecedora, uma vez que nos proporcionou utilizar os elementos dos games dentro do contexto didático, motivando os alunos à compreensão do conteúdo de forma lúdica.

A partir da experiência relatada, pudemos perceber que o uso das Metodologias Ativas, como a Gamificação, se apresenta como uma nova vivência do ensino/aprendizagem dentro da sala de aula além de possibilitar novas experiências na prática docente, elevando a um novo patamar de didática o relacionamento entre professor e aluno. 
Considerando a formação e a prática da primeira e da segunda autora, cabe destacar que esse projeto foi, sem dúvidas, um dos passos iniciais para construir um novo ensinar em matemática em nossas atuações profissionais. Além disso, para nós foi gratificante ver o envolvimento dos alunos durante o processo. No início estavam ressabiados e resistentes, todavia, ao longo do processo, foram se soltando, se envolvendo, discutindo resultados e novas possibilidades de resolver as questões. Ao final, quando recebemos ofeedback, pudemos concluir que a atividade ocorreu de forma mais que satisfatória, pois foram alcançados os objetivos propostos de engajamento e evolução de conteúdos e, mais que isso, conseguimos envolver e agradar os alunos que ficaram ansiosos pela próxima atividade de Gamificação.

A partir da experiência relatada, entendemos que as Metodologias Ativas podem atuar como agente de transformação na formação e na prática dos professores, pois abre espaço para que eles se desenvolvam e busquem estratégias para a implementação de novas abordagens nas aulas de matemática.

\section{Referências}

ARAÚJO, J. C. S. Fundamentos da metodologia de ensino ativa (1890-1931). In: REUNIÃO NACIONAL DA ANPED, UFSC, 37. 2015, Florianópolis. Anais [...]. Florianópolis, 2015.

BUSARELLO, R. I. Gamification: princípios e estratégias. 1. ed. São Paulo: Pimenta Cultural, 2016.

GEE, J. P. Situatedlanguageandlearning: a critique oftraditionalschooling. London: Routledge, 2004.

GEE, J. P. Bons videogames e boa aprendizagem. Perspectiva, Florianópolis, v. 27, n. 1, p. 167-178, jan./ jun. 2009.

KOPFLER, E.; OSTERWEIL, S.; SALEN, K. Movinglearning games forward, 2008. Disponível em: http://education.mit.edu/papers/MovingLearningGamesForward _EdArcade.pdf. Acesso em: 10 abr. 2019. 
MATTAR, J. Games em educação: como os nativos digitais aprendem. São Paulo: Pearson Prentice Hall, 2010.

RECH, G. A. Metodologias ativas na formação continuada de professores de Matemática, 2016. Dissertação (Mestrado Profissional em Ensino de Ciências Exatas) Programa de Pós-Graduação Stricto Sensu em Ensino de Ciências Exatas, UNIVATES, Lajeado, 2016.

SUITS, B.. 'Whats is a game?'. Philosophy of Science, v. 34, n. 2, p. 148-156, jun. 1967. Revisão da tradução de Lucas Miotto. 